\title{
DIVERSIFIKASI PRODUK OLAHAN MELINJO DALAM PENINGKATAN PEREKONOMIAN MASYARAKAT
}

\author{
Fitri Nurlaili \\ Universitas Banten Jaya, Jl. Syech Nawawi Albantani Serang Banten \\ Email: fitrinurlaili@unbaja.ac.id
}

\begin{abstract}
The aim of this Community Service program was to improve the economy of the society of Sangiang Village, Mancak District by providing knowledge and skills about diversification processing processed products of melinjo seeds. Service was carried out in several stages survey, socialization, procurement, packaging, labeling and promoting. The result of this dedication was the increase in society knowledge and skills regarding the processing of melinjo seeds into a variety of flavor variants that have not been done in Sangiang Village. This program was expected to improve the economy of the society by being able to increase the selling value of Melinjo products.
\end{abstract}

Keyword: Diversification, Economic, Melinjo.

\begin{abstract}
ABSTRAK
Tujuan program Pengabdian Masyarakat ini adalah untuk meningkatkan perekonomian masyarakat Desa Sangiang Kecamatan Mancak dengan cara pemberian pengetahuan dan keterampilan mengenai diversifikasi pengolahan produk olahan biji melinjo. Pengabdian dilakukan dengan beberapa tahap yaitu survey, sosialisasi, pengadaan bahan, pengemasan , pelabelan dan promosi. Hasil dari pengabdian ini adalah bertambahnya pengetahuan dan keterampilan masyarakat mengenai aneka ragam pengolahan biji melinjo menjadi berbagai macam varian rasa yang belum dilakukan di Desa Sangiang. Program ini diharapkan dapat meningkatkan perekonomian masyarakat dengan menambah nilai jual produk melinjo.
\end{abstract}

Kata Kunci: Diversifikasi, Ekonomi, Melinjo.

\section{PENDAHULUAN}

Kegiatan Kuliah Kerja Mahasiswa (KKM Tematik) merupakan salah satu bentuk pengintegrasian kegiatan pendidikan, penelitian dan pengabdian kepada masyarakat (LP3M, 2019: 1). Pada kegiatan KKM mahasiswa berada di tengah-tengah kehidupan masyarakat untuk membantu memecahkan permasalahan yang ada. Pada tahun 2019 KKM Tematik Universitas Banten Jaya berlokasi pada 24 desa pada 3 kecamatan di kabupaten Serang. Salah satu lokasi KKM- Tematik adalah desa sangiang kecamatan Mancak. Desa Sangiang berpenduduk 3.159 jiwa dengan 57\% penduduk berprofesi pada bidang pertanian dan perkebunan. Penduduknya berprofesi sebagai petani, buruh tani, buruh harian lepas, dan pekerja swasta. Tanaman yang paling banyak ditanam di desa ini adalah Melinjo. Melinjo ( Gnetum Gnemon L) merupakan salah 
satu komoditas lokal yang pemanfaatannya sangat kurang masih terbatas pada sayur dan bahan baku pembuatan emping.

Desa Sangiang memiliki 340 Hektare atau 24\% dari lahan desa yang menjadi lahan tanaman melinjo. Luasnya lahan melinjo tidak membuat warga desa sangiang menjadi pengrajin berbagai macam hasil pertanian yang berasal dari melinjo. Umumnya warga hanya menjual buah melinjo tanpa nilai tambah. Sehingga warga tidak memperoleh banyak keuntungan dari buah melinjo. Potensi buah melinjo belum dapat dioptimalkan oleh masyarakat, sehingga diperlukan upaya dari berbagai pihak untuk membantu memberikan keterampilan dan pengetahuan mengenai pemberian nilai tambah suatu produk yang akan meningkatkan perekonomian masyarakat desa Sangiang.

Untuk membantu memberikan pengetahuan dan keterampilan masyarakat desa Sangiang, bekerja sama dengan KKM- tematik Kelompok 2 Sangiang melakukan pengabdian kepada masyarakat mengenai penganekaragaman/ diversifikasi pengolahan biji melinjo. Diversifikasi dalam Kamus besar bahasa Indonesia diartikan sebagai perbedaan, penggolongan dan penganekaragaman. Diversifikasi produk umumnya perusahaan menaikkan penjualan dengan cara mengembangkan produk baru untuk pasar-pasar yang baru (Assauri, 2013: 218). Berdasarkan Khamidi (2013).diketahui bahwa diversifikasi produk dapat meningkatkan volume dan omzet penjualan, serta meningkatkan daya saing perusahaan. Pentingnya diversifikasi produk mendorong untuk dilakukannya pemberian keterampilan dan pengetahuan kepada masyarakat desa Sangiang mengenai diversifikasi produk olahan biji melinjo agar perekonomian masyrakat dapat meningkat.

\section{METODE}

Pelaksanaan kegiatan pengabdian kepada masyarakat ini dilakukan dengan beberapa tahap antara lain:

1. Survey

Dilakukan pendataan dan pengumpulan data terkait potensi dan permasalahan desa

2. Sosialisasi program

Sosialisasi merupakan kegiatan memasyarakatkan sesuatu sehingga menjadi dikenal, dipahami, dihayati oleh masyarakat. Kegiatan ini bertujuan untuk memberikan informasi terhadap warga desa calon peserta pelatihan

3. Pengadaan barang

Pengadaan bahan baku produksi dan bahan tambahan

4. Demonstrasi 
Demonstrasi adalah cara mengajarkan sesuatu dengan memperagakan dan mempertunjukkan tentang suatu proses, tahap yang sedang dipelajari. Pada kegiatan pengabdian masyarakat ini akan diperagakan oleh mahasiswa KKM Tematik Unbaja kelompok 2 desa Sangiang.

5. Pengemasan

Pengemasan merupakan kegiatan merancang dan memproduksi wadah untuk sebuah produk (Kotler, 2009: 27). Kemasan yang menarik akan mendorong kuantitas penjualan. Kemasan merupakan bagian pertama yang terlihat dari produk sehingga mampu menarik konsumen untuk melakukan pembelian.

6. Pelabelan

Pelabelan adalah kegiatan memberi label berupa informasi singkat mengenai produk.

7. Promosi

Promosi merupakan kegiatan mengkomunikasikan barang yang ditawarkan agar konsumen mengenal kemudian melakukan pembelian.

\section{HASIL DAN PEMBAHASAN}

Kegiatan survey lapangan dilakukan pertama kali pada Ahad, 28 Juli 2019, survey dimaksudkan untuk mengetahui lokasi desa dan berbagai potensi yang dapat digali dari Desa Sangiang Kecamatan Mancak. Dari survey awal diketahui bahwa desa Sangiang memiliki potensi hasil petanian berupa tanaman melinjo, namun berdasarkan wawancara dengan aparat desa diketahui bahwa warga belum mengoptimalkan potensi karena masih menjual melinjo dalam bentuk bahan mentah yang belum terolah. Salah satu hambatan yang ditemui adalah akses transportasi yang terbatas sehingga warga kesulitan dalam pendistribusian hasil pertanian tersebut sehingga langsung menjual bahan mentah kepada pengepul yang mengakibatkan nilai jual melinjo relatif rendah.

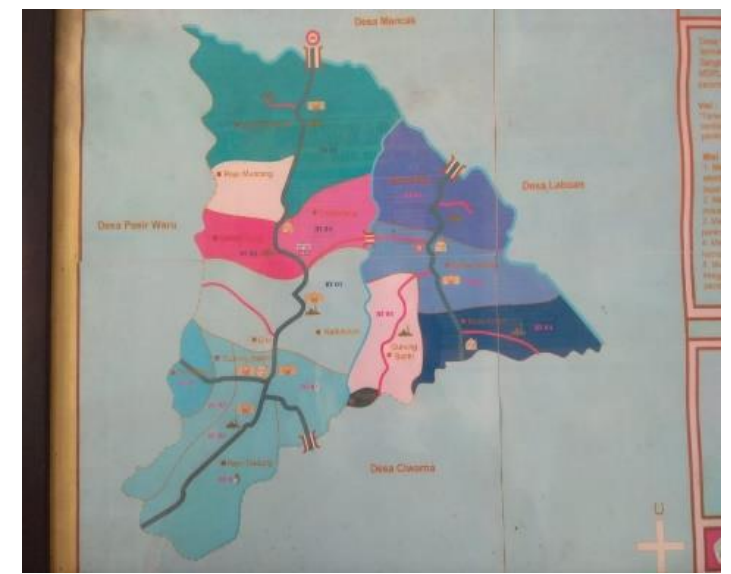

Gambar 1. Wilayah Desa Sangiang Kec. Mancak 


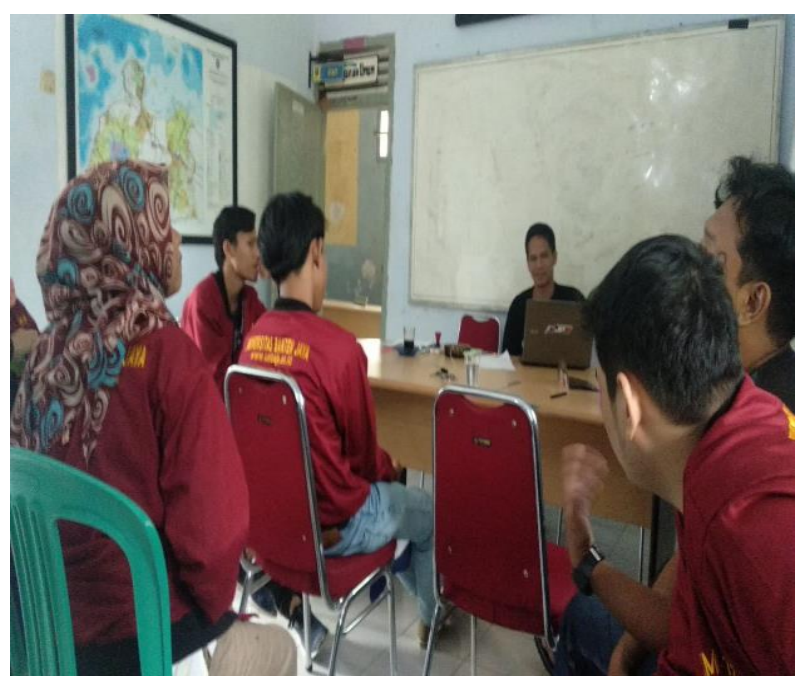

\section{Gambar 2. Wawancara dengan Aparat Desa Sangiang}

\section{Sosialisasi}

Sosialisasi dilaksanakan pada tanggal 15 Agustus 2019 bertempat di salah satu rumah penduduk. Kegiatan berlangsung dengan lancar serta diikuti dengan sangat antusias oleh warga. Materi yang diberikan mengenai aneka ragam pengolahan produk biji melinjo, masyarakat desa sangiang pada dasarnya telah mampu mengolah melinjo menjadi ceplis namun masih terbatas pada rasa original yaitu gurih. Sosialisasi ini memberikan pengetahuan bahwa penganekaragaman produk kuliner ceplis menjadi berbagai macam rasa akan meningkatkan perekonomian warga.

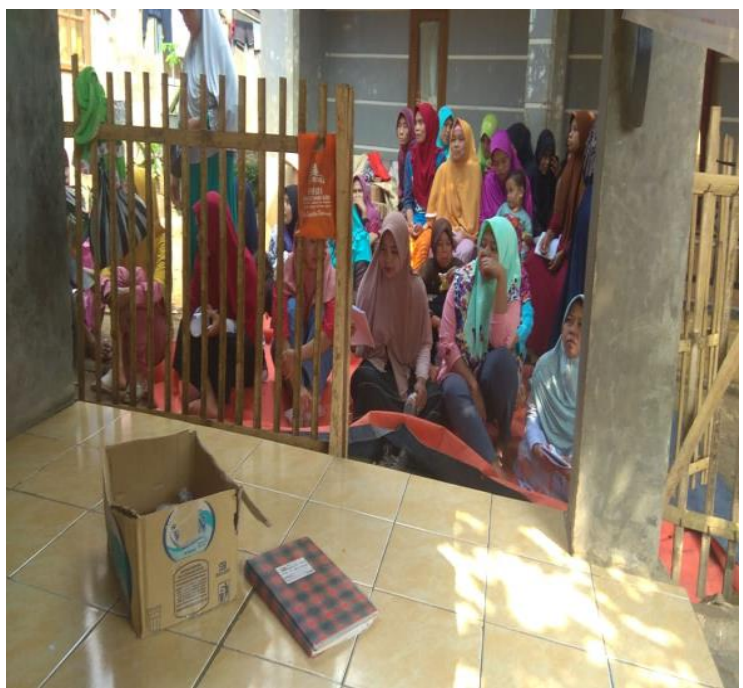

Gambar 3. Sosialisasi Program Pelatihan 


\section{Pengadaan Barang}

Pengadaan barang berlangsung pada Kamis, 22 Agustus 2019. Pengadaan bahan mentah digunakan untuk memenuhi kebutuhan produksi, pengadaan bahan mentah utama berupa biji melinjo dilakukan pada pengepul yang berada di desa sangiang dengan harga Rp. 10.000/ Kg Untuk pembuatan ceplis dipilih buah melinjo yang telah masak yaitu yang telah berwarna merah. Setelah dilakukan pembelian dilakukan pengupasan kulit melinjo dan disimpan. Sebagai bahan penunjang seperti cabe, bawang putih, gula dan garam dilakukan pada pasar desa. Sedangkan bumbu instan rasa barbeque dibeli di kota serang. peralatan yang akan digunakan untuk pelatihan menggunakan peralatan milik warga sekitar.

\section{Demontrasi}

Demonstrasi pengolahan produk berbasis biji melinjo dilaksanakan pada Jumat 23 Agustus 2019 bertempat di posko KKM- Tematik Kelompok 2 Desa Sangiang Kecamatan Mancak. Kegiatan ini diikuti secara intensif oleh 7 orang ibu rumah tangga namun dihadiri 21 orang peserta. 14 antusias mengikuti kegiatan ini walaupun tidak perperan serta aktif. Demontrasi pembuatan ceplis dimulai dengan mensangrai biji melinjo yang sudah dikupas menggunakan pasir dengan suhu tinggi, biji melinjo disangrai sampai menghitam selama sekitar 3-4 menit. Setelah itu kupas kulit bagian dalam. Setelah pengelupasan kulit, geprek biji melinjo dalam keadaan masih panas agar mudah terbentuk. Setelah digeprek biji melinjo langsung digoreng agar tekstur ceplis renyah.

Pada tahap pertama seluruh peserta telah mengetahui cara pembuatannya. Namun untuk meningkatkan nilai tambah suatu produk diperlukan kreativitas dan inovasi baru agar diperoleh segmen pasar baru. Diversifikasi Produk olahan biji melinjo dimulai pada tahap ini warga dikenalkan dengan berbagai ragam rasa yang lebih dekat dengan segmen pasar usia muda. Diversifikasi rasa pada olahan ceplis yaitu menambah rasa dari rasa gurih menjadi ceplis balado dan ceplis barbaque. Ceplis balado terbuat dari ceplis orginal yang ditambahkan bumbu asli balado. Bumbu balado terdiri dari terbuat dari bahan-bahan original seperti cabe besar merah, bawang putih, daun salam, serai daun jeruk serta dilengkapi dengan gula merah dan garam. Pertama-tama cabai merah besar dan bawang putih dihaluskan kemudian disangrai sampai harum kemudian ditambahkan daun salam, serai dan daun bawangdiaduk sampai merata. Tambahkan sisiran gula merah dan garam, tambahkan dengan air biarkan sampai mengental dan meletup-letup. Seteleh bumbu mengental tambahkan ceplis aduk hingga merata kemudian didinginkan. 
Bumbu balado untuk ceplis ini tidak menggunakan bawang merah dikarenakan bawang merah akan membuat ceplis menjadi lebih cepat melempem. Melempemnya produk ceplis akan mengurangi kenikmatan rasa padahal produk akan dijual ke luar desa sangiang. Keanekaragaman lain yang ditambahkan pada produk ini adalah rasa barbeque. Rasa barbeque merujuk pada cita rasa asam, manis, gurih dan sedikit pedas. Rasa ini belum familier bagi warga desa sangiang. Hal ini tentu merupakan salah satu daya tarik dari ceplis ini.

Ceplis rasa barbeque menggunakan bumbu tabur instan. Penggunaan bumbu instan dirasa lebih praktis dan menekan biaya produksi bumbu. Penggunaan bumbu barbeque instan dirasa lebih murah dibandingkan dengan membuat bumbu dengan bahan baku original. Perbedaan keanekaragaman rasa dan bumbu juga mengarah kepada segmen pasar yang berbeda. Ceplis rasa balado mengarah kepada konsumen usia dewasa yang menyukai rasa asli suatu masakan. Sedangkan ceplis rasa barbeque mengarah pada segmen pasar anak muda yang menyukai pengalaman berbeda dari kebiasaannya. Rasa baru akan menimbulkan keingintahuan yang akan mengarah kepada pembelian produk.
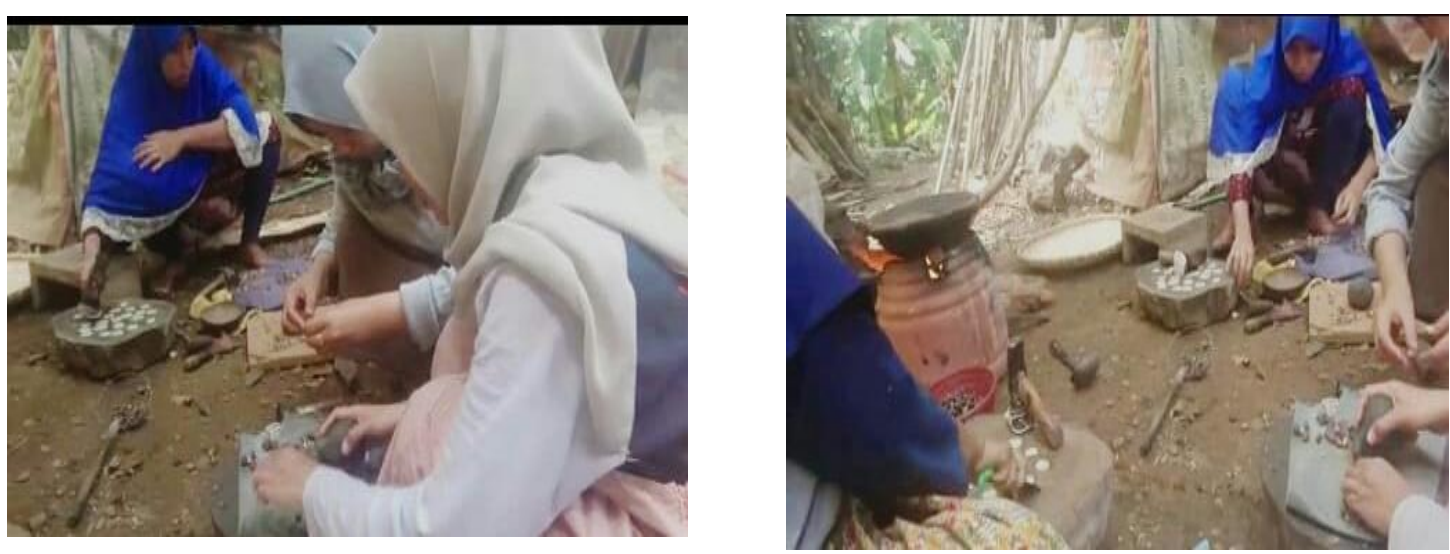

\section{Gambar 4. Demonstrasi Pengolahan Biji Melinjo}

\section{Pengemasan}

Dewasa ini keputusan pembelian suatu produk bukan hanya dipengaruhi oleh rasa ataupun harga produk tersebut. Kemasan juga memiliki peranan yang penting dalam keputusan pembelian. Pengemasan yang menarik akan membuat calon konsumen mempertimbangan untuk membeli produk yang ditawarkan. Pengabdian kepada masyarakat ini selain mengenalkan aneka ragam rasa olahan biji melinjo juga mengajak kepada para peserta untuk mempertimbangkan cara pengemasan produk. Pengemasan yang menarik akan lebih meyakinkan konsumen mengenai produk yang dihasilkan. 
Pengemasan olahan produk biji melinjo ini dilakukan menggunakan standing pouch berukuran 12 X 20 pemilihan standing pouch dikarenakan kemasan makanan sebaiknya kedap udara dan kedap air. Bahan baku standing pouch adalah plastik yang relatif tebal dan memiliki sealer, sehingga lebih meyakinkan konsumen atas keamanan produk. Plastik yang tebal akan memberikan kesan lebih eksklusif serta dapat menghindarkan produk dari kontaminasi dari luar. Penggunaan standing pouch juga akan menjaga kualitas ceplis karena adanya sealer sehingga tidak ada udara yang masuk, hal ini menjaga kerenyahan produk ceplis serta memudahkan konsumen dalam membuka ataupun kembali menutup kemasan ketika produk belum habis dikonsumsi. Pengemasan dengan bahan baku plastik juga dikarenakan kedap air. Karena ceplis akan menurun kualitasnya apabila terkena air. Pengemasan produk ceplis menggunakan standing pouch juga mempertimbangkan ergonomi. Kemasan dengan ukuran ini mudah dibawa sehingga memudahkan pengiriman produk kepada konsumen. Pemilihan ukuran kemasan juga mempertimbangkan besaran harga jual produk. Dengan ukuran ini ditetapkan harga Rp. 8.000 untuk ceplis original, Rp. 10.000 untuk ceplis barbeque dan Rp. 12.000 untuk ceplis balado. Dengan harga tersebut diharapkan dapat terjangkau oleh konsumen sasaran.

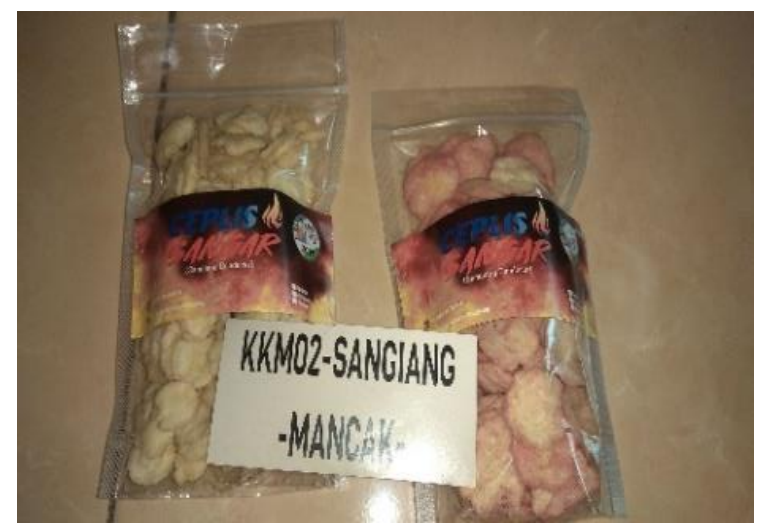

Gambar 5. Kemasan Ceplis

\section{Pelabelan}

Kegiatan setelah pengemasan adalah pemberian label pada kemasan. Label memuat nama merk, produsen produk, dan informasi terkait produk. Penggunaan label dimaksudkan untuk mengidentifikasi produk, menggambarkan produk, dan mempromosikan produk. Mengidentifikasi produk dimaksudkan untuk membedakan produk dengan produk lain yang sejenis, menggambarkan produk dimaksudkan untuk memberikan informasi mengenai produk tersebut, dan mempromosikan produk dimaksudkan untuk mengenalkan produk pada calon konsumen. 
Label pada produk yang dihasilkan masyarakat Desa Sangiang ini memuat merk produk yaitu "Ceplis Sangar" dengan latar belakang warna merah dan hitam serta terdapat gambar api, label juga mencantumkan identitas produsen yaitu KKM 02 Sangiang Mancak dan informasi terkait produk tersebut yakni ceplis. Sangar dalam KBBI mengarah pada arti kata angker, ini menunjukkan varian rasa yang dimiliki produk ini adalah rasa balado yang pedas, padahal Pemilihan Merk "Ceplis Sangar" mengarah pada desa asal produk tersebut yaitu Sangiang Gandaria. Makna ganda dari produk ini diharapkan memancing keingintahuan calon konsumen mengenai produk. Pemilihan Gambar dan warna yang dirancang pada label produk ini juga mengidentifikasikan bahwa produk memiliki varian rasa yang pedas, warna merah dan hitam serta gambar api akan lebih memperkuat image konsumen mengenai rasa produk ini.

\section{Promosi}

Promosi dalam penjualan produk pada awalnya dilakukan dengan mulut ke mulut ( word of mouth). Promosi ini dilakukan dengan merekomendasikan produk secara individu kepada calon konsumen. Promosi yang dilakukan ini masih terbatas kepada orang-orang yang berada disekitar produsen. Hal ini berakibat masih terbatasnya cakupan penjualan produk. Salah satu kelemahan desa Sangiang adalah sulitnya akses transportasi keluar desa. Sehingga produkproduk yang dihasilkan sulit untuk dijual keluar daerah. Pada kegiatan pengabdian ini dilakukan usaha menjual produk olahan melinjo Ceplis Sangar kepada masyarakat di luar Desa Sangiang.

Produk Ceplis Sangar pertama kali diperkenalkan kepada masyarakat luar desa Sangiang pada saat kegiatan Bazar pelepasan KKM Kecamatan Mancak. Kegiatan Bazar merupakan rangkaian acara seminar kewirausahaan dengn tema" Sentra Emping Menjadi Tamu di Rumah Sendiri”, pemilihan tema dikarenakan Mancak sebagai daerah penghasil emping namun belum tergali potensinya dengan baik.

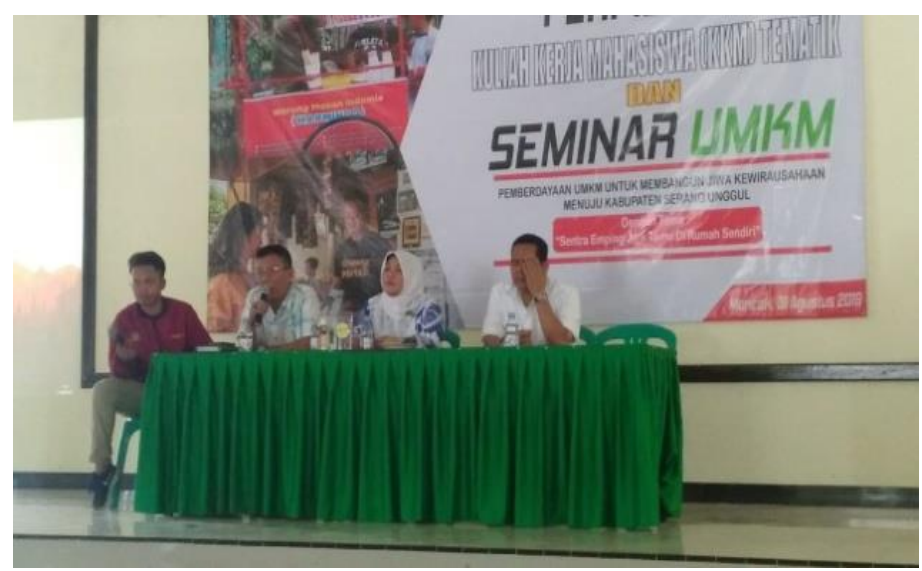

Gambar 6. Seminar Kewirausahaan 


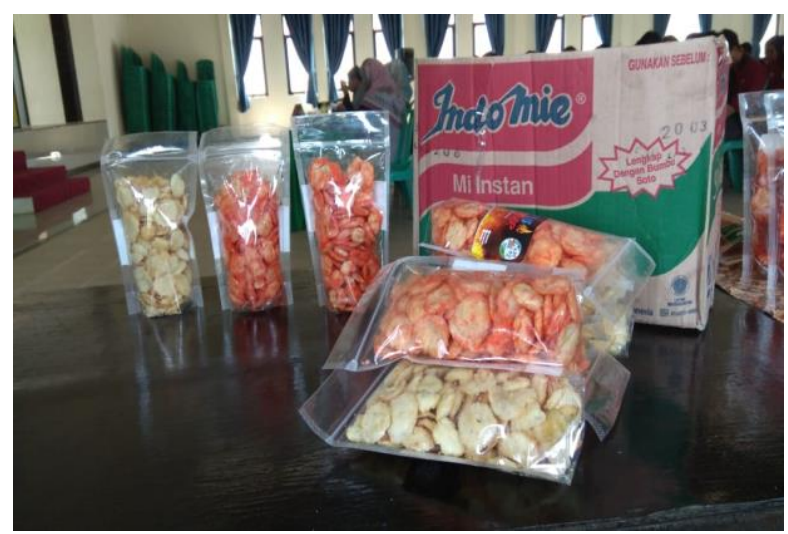

Gambar 7. Bazar Produk Ceplis Sangar

Kegiatan bazar ini dihadiri oleh lebih dari 250 peserta, dengan bazar ini produk ceplis sangar dipromosikan kepada khalayak luas. Dengan acara ini diharapkan semakin banyak masyarakat yang mengenal produk Ceplis Sangar sehingga meningkatkan penjualan dan berpengaruh kepada peningkatan perekonomian warga desa Sangiang

\section{KESIMPULAN}

Kegiatan pengabdian masyarakat ini bertujuan untuk meningkatkan perekonomian masyarakat desa sangiang dengan memberikan pengetahuan dan keterampilan tentang diversifikasi produk olahan biji melinjo yang akan meningkatkan nilai tambah produk olahan biji melinjo. Setelah dilakukan pengabdian kepada masyarakat ini diharapkan masyarakat terus kreatif dan inovatif dalam mengoptimalkan potensi yang dimiliki berupa olahan biji melinjo. Berdasarkan kegiatan seminar kewirausahaan diperoleh masukan untuk penambahan informasi pada label produk, disarankan pula untuk memperkuat promosi terutama menggunakan daring agar ceplis sangar lebih dikenal masyarakat yang lebih luas.

\section{DAFTAR PUSTAKA}

Assauri, Sofjan. ( 2015). Manajemen Pemasaran. Jakarta: Rajawali Press

Kamus Besar Bahasa Indonesia. https://kbbi.kemdikbud.go.id/

Kotler, Philip\& Kevin Lane Keller.( 2009). Manajemen Pemasaran jilid 2 Edisi 13. Jakarta: Erlangga

LP3M .(2019). Buku Panduan Kuliah Kerja Mahasiswa( KKM) Tematik UNBAJA 2019. Serang: Universitas Banten Jaya

Khamidi, Sofwan, Achmad Fauzi DH, Imam Suyadi. (2013). Pengaruh Diversifikasi Produk Terhadap Penjualan( Studi Kasus Pada Perusahaan Konveksi” Faiza Bordir” Bangil. 
ISSN : 2686-6447

Jurnal ABDIKARYA

E-ISSN : 2715-6605

Volume 1, No. 1, Oktober 2019

$\begin{array}{llllll}\text { Pasuruan. Jurnal Administrasi } & \text { Bisnis } & \text { Vol } & 5 & \text { No }\end{array}$

http://administrasibisnis.studentjournal.ub.ac.id/index.php/jab/article/view/240/414 